\title{
Implicações do Estudo do Letramento
}

Juçara Benvenuti*

Resumo: Este artigo apresenta os estudos sobre letramento que realizei para responder às questões que desencadearam meu projeto de Doutorado: Como a escola pode realizar um trabalho produtivo e atingir o público leitor contemporâneo? Como ensinar leitura literária na aula de Língua Portuguesa do Ensino Médio para Jovens e Adultos que tiveram uma história diferenciada de inserção social no mundo letrado? O aprofundamento desse tema ocorreu através de vasta bibliografia que inclui autores brasileiros e estrangeiros, como Barton, Cosson, Heath, Kato, Kleiman, Street, Tfouni, entre outros. A principal justificativa desse estudo é a busca pelo entendimento do que acontece em sala de aula: alguns alunos alcançam melhores resultados em certas atividades, outros terminam as tarefas mais rapidamente $\mathrm{e}$ outros, às vezes, nem conseguem realizá-las a contento. A diferença nos resultados se deve ao grau de letramento individual, que pode ser independente do tempo de escolarização do aluno, pois depende de fatores como o grau de inserção do indivíduo e de suas relações na sociedade em que vive. Com esse conhecimento foi possível pensar uma forma de atingir o desenvolvimento do letramento literário de alunos de EJA.

Palavras-chave: Eventos e Práticas de Letramento; Letramento Autônomo e Ideológico; Letramento Literário.

Abstract: This paper presents the study of literacy that I did in my $\mathrm{PhD}$ to answer the questions that triggered my project:

* Doutora em Linguística Aplicada pelo Instituto de Letras da UFRGS. Professora do Colégio de Aplicação e do Curso de Especialização PROEJA da FACED/UFRGS. Coordenadora da Educação de Jovens e Adultos do CAp/UFRGS. E-mail: 00010456@ufrgs.br 
How the school can work productively and reach contemporary readers? How to teach reading in the literary class of the Portuguese Language School Youth and Adults who had a distinguished history of social integration in the literate world? The deepening of this theme occurred through extensive bibliography that includes Brazilian and foreign authors such as Barton, Cosson, Heath, Kato, Kleiman, Street, Tfouni, among others. The main reason of this study is the search for understanding what happens in the classroom: some students achieve better results in certain activities, other finish tasks more quickly and others sometimes can not even perform them satisfactorily. The difference in results is due to the individual degree of literacy, which can't dependent of schooling, it depends on such factors as the degree of integration of the individual and their relationships in society where he lives. With this knowledge it was possible to think of a way to achieve the development of literary literacy of students in adult education.

Keywords: Events and Literacy Practices; Autonomous and Ideological Literacy; Literacy Literary.

\section{Introdução}

A necessidade de conhecer profundamente o tema 'Letramento' surgiu durante o meu Doutorado, quando passei a analisar a experiência que realizei e serviu de base para a construção da minha proposta de currículo para Educação de Jovens e Adultos. Foram três semestres letivos de aulas de Literatura, correspondentes às três séries do Ensino Médio na modalidade de EJA.

Entre outras observações que fiz, destaco o fato de encontrar alunos que obtinham melhor aproveitamento que outros, nos mesmos tipos de atividades desenvolvidas em diferentes condições e situações; ou, então, de alguns que terminavam rapidamente suas tarefas em certas ocasióes e em outras não conseguiam realizá-las.

Para discutir de forma organizada esse assunto amplo, divido o artigo em quatro tópicos, a saber: Conceitos Básicos, 
Eventos e Práticas de Letramento, O Binômio Proposto por Street: Letramento Autônomo e Ideológico, e Letramento Literário.

\section{Conceitos Básicos}

O termo 'letramento' é uma tradução de literacy e foi usado pela primeira vez no Brasil por Mary Kato na obra No mundo da escrita: uma perspectiva psicolinguistica, publicado em 1986, segundo Soares (1998) e Kleiman (1995). Antes do surgimento desse termo, a palavra alfabetização dava conta de duas significações: a primeira referia-se à aquisição da tecnologia da escrita e a segunda, à inserção do indivíduo no mundo da escrita. Dessa forma, para que o leitor entendesse o significado desejado pelo autor, tornava-se necessária uma explicação do termo.

Com a nova palavra, os dois processos tornaram-se distintos: agora podemos dizer que a alfabetização é o processo pelo qual o indivíduo adquire o domínio de um código e das habilidades de utilizá-lo para ler e escrever, que nada mais é do que o domínio da tecnologia da escrita, enquanto o letramento refere-se à aquisição da referida tecnologia e a seu uso competente nas práticas sociais de leitura e escrita (cf. SOARES, 2003).

Considero inegável a facilidade que o novo termo trouxe para a comunicação, no entanto, seu uso ainda é relativamente recente. Acredito que seja por isso, que há algumas pessoas que continuam usando indistintamente a palavra 'alfabetização'; enquanto outras, mesmo (re)conhecendo o termo 'letramento', como é o caso de Emília Ferreiro, reafirmam sua filiação e preferência por 'alfabetização'.

Outro aspecto diz respeito às obras escritas alguns anos antes do novo conceito difundir-se no meio acadêmico. Freire, por exemplo, usa o termo alfabetização, mas não com o sentido único de domínio da tecnologia de leitura e escrita. Para ele, tratase de uma prática educativa que só pode alcançar efetividade e eficácia na medida da participação livre e crítica dos educandos, 
através de uma tomada de consciência do alfabetizando em um processo mediatizado pelo diálogo entre o coordenador e o grupo chamado Círculo de Cultura. Assim, o debate de temas geradores precede o desenvolvimento da técnica de ler e escrever.

Com esses esclarecimentos justifico o uso dos dois termos em meu trabalho. Acompanho a terminologia escolhida pelos autores que cito, mas deixo clara sua intenção na opção por um ou outro. Particularmente concordo com a nova orientação, porque distingue os dois processos e permite aumentar sua abrangência. Sob esse aspecto, explico melhor.

Nascido na área na Linguística, o termo letramento tem sido ampliado a outras áreas do conhecimento, modificando seu significado original. Tanto tem servido para designar as práticas sociais de leitura e escrita, quanto para práticas de outra natureza. Já ouvimos falar em letramento tecnológico, religioso, digital, literário.

A escola tradicionalmente tem sido responsabilizada pelo acesso à tecnologia da leitura e da escrita e pela aprendizagem das habilidades e atitudes necessárias para seu uso nas práticas sociais, que são conhecidas respectivamente por alfabetização e letramento ${ }^{1}$. São vistas como aquisição da escrita, alfabetização, as técnicas constituídas pelos procedimentos e habilidades de decodificação dos sinais gráficos, habilidades motoras para usar instrumentos para a realização da decodificação e até a manipulação dos suportes de escrita e leitura. Ao letramento cabe o uso efetivo e competente da tecnologia da escrita, que implica o desenvolvimento de capacidades como ler e escrever variados gêneros, interpretar, comparar.

No entanto, cabe salientar que a alfabetização não é prérequisito para o letramento, como se comprova pelas análises das

A definição e diferenciação entre alfabetização e letramento aparecem pela primeira vez na literatura educacional brasileira, em 1988, na introdução do livro "Adultos não alfabetizados: o avesso do avesso", escrito por Leda Maria Tfouni. Internacionalmente o termo aparece nos trabalhos de Barton, Street, Gee e Heath chamados de teóricos dos Novos Estudos do Letramento, em inglês New Literacies Studies (NLS). 
pesquisas do Indicador de Alfabetismo Funcional (INAF) ${ }^{2}$, as quais mostram que pessoas com baixa ou nenhuma escolaridade apresentaram alto desempenho no teste, enquanto que outras com alta escolaridade, nível superior completo e incompleto, não se saíram bem³ .

Além disso, vale lembrar ainda que países desenvolvidos como os Estados Unidos, a França e a Inglaterra, os quais já erradicaram o analfabetismo, apresentam número alto de pessoas com dificuldades para utilizar a leitura e a escrita em tarefas cotidianas. Esses dados evidenciam que o problema não é com o nível de alfabetismo, mas com as práticas sociais ligadas ao letramento.

As pessoas que realizam atividades cotidianas em uma sociedade grafocêntrica, mesmo aquelas que ainda não dominam os códigos gráficos para realizarem suas próprias leituras e escrituras, não podem ser consideradas iletradas, pois não há como thes atribuir grau zero de letramento. De alguma forma essas pessoas interpretam as informações que precisam e se locomovem pela cidade, tomando ônibus; fazem compras no supermercado, escolhendo produtos; se comunicam com outras pessoas, usando "estratégias orais letradas" (TFOUNI, 1988); enfim, realizam

2 "O INAF - Indicador de Alfabetismo Funcional - é um indicador que mede os níveis de alfabetismo funcional da população brasileira adulta. O objetivo do INAF é oferecer à sociedade informações sobre as habilidades e práticas de leitura, escrita e matemática dos brasileiros entre 15 e 64 anos de idade, de modo a fomentar o debate público, estimular iniciativas da sociedade civil e subsidiar a formulação de políticas nas áreas de educação e cultura” (Instituto Paulo Montenegro. In: <http://www. ipm.org.br/ipmb_pagina.php?mpg $=4.01 .00 .00 .00 \&$ ver $=$ por $)>$. Acesso em: 12 abr. 2010.) Em 2001, 2003 e 2005 foram medidas as habilidades de leitura e escrita (letramento) e em 2002 e 2004, as habilidades matemáticas (numeramento). A partir de 2007, a pesquisa passou a ser bienal, trazendo simultaneamente as habilidades de letramento e numeramento e mantendo a análise da evolução dos índices a cada dois anos.

3 Os casos que surpreenderam por suas relaçôes inesperadas, receberam análise detalhada das professoras Marta Kohl de Oliveira e Cláudia Lemos Vóvio, publicadas no livro Letramento no Brasil de Vera Masagão Ribeiro de 2003, e compreendem oito pessoas que se autodeclararam analfabetas ou que afirmaram ler e escrever sem ter frequentado a escola, as quais alcançaram os dois níveis mais altos no teste. Em contrapartida, dos cinco casos que ficaram no nível mais baixo de alfabetismo, dois declararam ter nível superior incompleto e três, completo (RIBEIRO, 2003). Os dados referidos são das pesquisas de 2001 e 2003. 
suas tarefas diárias e vivem. Essas pessoas podem ser chamadas de não-alfabetizadas, mas não podem ser chamadas de iletradas.

Os estudos realizados por Soares (2003), a partir das análises dos dados do INAF, tentam explicar a discrepância entre grau de instrução e nível de letramento, desvinculando a escola dessa responsabilidade. Soares lembra que pode ter ocorrido uma 'reversão' a níveis de habilidades inferiores aos já atingidos pelo processo de escolarização devido a pouco ou nenhum uso da leitura e escrita, por variadas causas. Além disso, a pessoa pesquisada pode ter estranhado a situação 'teste' por ter ficado afastada muito tempo das avaliações escolares ou não ter desenvolvido aquelas habilidades específicas na época de sua escolarização. Outra questão ainda foi levantada por Soares: pode ocorrer um distanciamento entre o letramento escolar e o social ou não escolar, fato que explicaria o baixo desempenho no teste de pessoas com alto nível de escolaridade.

A análise descrita acima se atém aos resultados de baixo grau de letramento, mas o que poderia ter acontecido nos casos em que as pessoas têm baixos níveis de escolaridade e alcançaram graus de letramento mais elevados? O letramento não ocorre apenas no período da alfabetização ou na escola, ele se estende por toda a vida da pessoa e de acordo com as práticas sociais que os indivíduos têm pode ir mudando. O letramento, portanto, é um processo contínuo que faz parte de sociedades letradas, e como tal leva as pessoas a participarem, direta ou indiretamente, de muitas práticas letradas no cotidiano, proporcionando-lhes aumento no nível de letramento.

Para entender melhor o que foi dito é preciso conhecer os conceitos de eventos e práticas de letramento. O primeiro foi proposto por Heath, o segundo por Street, ambos são discutidos por Barton e se constituem "chaves para a compreensão do letramento como fenômeno social”" (HEATH, 1982, p. 48).

$4 \quad$ [Tradução minha] : "key to understanding literacy as a social phenomenon" (HEATH, 1982, p. 48). 


\section{Eventos e Práticas de Letramento}

Shirley Brice Heath realizou uma grande pesquisa nas comunidades Maintown, Roadville e Trackton, que se situam próximas uma das outras na região chamada Piedmont Carolinas no sudeste dos Estados Unidos para verificar o desenvolvimento da linguagem das crianças durante as horas que não estavam na escola. O relato completo dessa investigação está no livro Ways with Words: Language, Life and Work in Communities and Classrooms (1996, 1983).

De forma mais condensada, Heath apresenta em What no bedtime story means: narrative skills at home and school (o capítulo 13 da obra Linguistic Anthropology de Alessandro Duranti) os mesmos relatos, com sua análise. Com esse trabalho, Heath (2001) nos mostra que cada comunidade tem sua própria história de letramento e que não há um modelo a ser seguido. As características de letramento de cada comunidade são as responsáveis pelas diferenças no desenvolvimento do letramento das crianças.

As práticas de base cultural da comunidade originam habilidades específicas, as quais podem ser ou não reconhecidas pela escola. Os indivíduos que dominam as habilidades privilegiadas pela escola são avaliados diferentemente daqueles que não as possuem. Assim, o que marca as crianças é o que lhes falta, o seu deficit. E o que fazem os professores quando a criança é desse modo avaliada? Tentam sobrepor ou mesmo impor uma orientação diferente.

Em virtude do acima exposto, creio não ser exagero dizer que o desconhecimento da orientação de letramento do grupo social a que pertencem os indivíduos, que participam da escolarização, dificulta a compreensão das necessidades por eles apresentadas. Assim, destaco a importância de um(a) pesquisador(a), como Heath, observar por uma década o desenvolvimento das crianças das comunidades pesquisadas.

Não pensando em reduzir o trabalho de Heath, mas querendo destacar alguns pontos, quero falar um pouco da pesquisa 
sobre a comunidade de Trackton. Heath (1982) descreve as observaçôes que fez com as crianças da cidade e depois com os adultos. Concluiu que a aprendizagem é orientada muito mais por contextos particulares do que pela instrução intencional, e que ocorre através da exposição ao uso da linguagem cotidiana.

A comunidade, mesmo sendo alfabetizada, usa mais a comunicação oral do que a escrita. Relata Heath(1982) que observou que eles usam o material escrito de forma única e para propósitos bem definidos; a leitura é muito mais uma atividade social, por isso o seu significado não reside apenas no texto, mas na interação dos membros da comunidade. Além disso, afirma Heath (1982), os textos impressos são traduzidos para o modo oral, como pôde observar nas leituras de cartas ou da Bíblia e nos empregos em que alguém escreve para os funcionários.

O desenvolvimento oral das crianças não é estimulado pelos adultos, pois parecem não acreditar na relação diádica mãe/ filho. Segundo Heath (1982), há muitas situações que merecem relato, mas selecionei algumas para comentar. Quando os adultos discutem significados de textos (como os casos mencionados, de textos religiosos ou de cartas) as crianças ficam por perto; e não é raro verificar as crianças ficcionalizando histórias reais para chamar a atenção dos adultos.

Outro dado apresentado pela pesquisadora e altamente relevante para o estudo do letramento, diz respeito à forma como a igreja de Trackton atua. Heath (1982) constatou que a igreja não só realiza leituras, orações, cantos de hinos, discussão de textos da Bíblia, como também exige que eles sejam entregues por escrito.

Para falar dessas situações, Heath criou o termo 'eventos de letramento', que, então, podem ser considerados “qualquer ocasião [de interação] em que a escrita é parte integrante da natureza das interações entre os participantes e de seus processos interpretativos" (1982, p. 50) $)^{5}$. A interação entre as pessoas nos

[Tradução minha]: "any occasion in which a piece of writing is integral to the nature of participants' interactions and their interpretive processes" (HEATH,1982, p. 50). 
eventos pode ocorrer face a face ou a distância, isto é, podem discutir um texto pessoalmente ou por intermédio de outros recursos ou vias, realizar a leitura de um texto, escrever alguma coisa para alguém.

As formas de interação dependem da cultura da comunidade e dos hábitos dos indivíduos decorrentes dela. Mas aí, já estamos chegando a outra área de estudos, representada pelo professor e escritor Brian Street que atua na Universidade de Londres.

Street é responsável pelo conceito de práticas de letramento, e diz que se referem a uma concepção cultural mais ampla de formas particulares de pensar e ler e de escrever em contextos culturais e incluem os modelos sociais de letramento utilizados pelos participantes e os significados atribuídos a esses eventos de letramento (1984).

A partir desse enfoque, Street busca eliminar a dicotomia entre oralidade e escrita, que era vista como pressuposto para os processos de letramento, e mostra que há interligação entre os códigos e registros das modalidades linguísticas, pois os sentidos são "negociados e construídos na interação" (idem). Conforme ensina Heath, as combinações e os sentidos construídos nas comunidades variam de grupo para grupo e também de acordo com as finalidades de seu uso.

A apropriação desses sentidos e combinações, internas às comunidades, são apreendidas desde cedo pelas crianças em práticas do cotidiano, não são escolarizadas. Dessa forma, quando práticas escolarizadas com outros padrões culturais são impostas, educadores e pesquisadores alheios àquela comunidade pensam em déficits cognitivos e/ou linguísticos dos indivíduos.

Portanto, essas categorias, 'práticas e eventos de letramento', permitem compreender que o indivíduo só se torna leitor ou escritor quando vincula a capacidade de leitura e de escrita diretamente aos eventos de letramento dos quais participa, mediados pelas práticas de letramento; caso contrário, a leitura e a escrita não possuem significação, uma vez que não farão parte dos objetivos socialmente determinados. 
Esse parece ser o caso apontado por Heath, em seu estudo dos funcionários de empresas de Trackton, que não escrevem, usam a forma oral apenas, uma pessoa é determinada para escrever por todos. Sem precisar da forma escrita, usam a oralidade para a comunicação. Isso não quer dizer que não reconheçam a escrita, mas quer dizer que seus hábitos culturais são diferentes de outras localidades, provando que os eventos de letramento são distintos em cada comunidade.

Em acordo com as ideias expostas por Heath e Street, Barton afirma que "eventos de letramento estão ligados, de modo particular, a comunidades específicas em pontos específicos da história" $(1994, \text { p. } 3)^{6}$ ou seja, não existe uma forma de letramento, mas sim eventos de letramento que são específicos de determinadas comunidades e se modificam com o passar do tempo. E descreve evento de letramento como "uma ocasião na qual uma pessoa busca compreender ou produzir sinais gráficos [...] sozinha ou com outras pessoas"7 (ibidem, p. 36). Para ele, assim como para os demais pesquisadores do grupo New Literacy Studies (NLS), os eventos se constituem como acontecimentos sociais, tendo como base um texto, tanto para compreendê-lo quanto para produzi-lo.

Barton ainda reforça que as práticas de letramento são uma categoria mais ampla e abstrata: "Práticas de letramento são os modos mais gerais, ligados à cultura, de utilizar o letramento, aos quais as pessoas recorrem num evento de letramento"s (ibidem, p. 37). Os eventos fazem parte das práticas, uma vez que são formas culturais de utilização do letramento. São as práticas sociais que determinam o uso da leitura e da escrita em uma situação específica, dando ao letramento uma função.

6 [Tradução minha]: "literacy events are particular to a specific community at a specific point in history" (BARTON, 1994, p. 3).

7 [Tradução minha]: "an occasion when a person attempts to comprehend or produce graphic signs [...] either alone or with others” (BARTON,1994, p. 36).

8 [Tradução minha]: "Literacy practices are the general cultural ways of utilizing literacy which people draw upon in a literacy event" (BARTON, 1994, p. 37). 
Assim, desde os mais rotineiros hábitos, como observar um folder promocional, escolher um produto no supermercado pelo rótulo, ouvir um noticiário, ler um jornal, ou discutir o conteúdo de um texto, as pessoas estarão realizando práticas letradas. $\mathrm{O}$ letramento se relaciona diretamente com as experiências de vida de cada pessoa, como Barton afirma: "As pessoas detêm letramentos dos quais fazem uso, estes estão associados a diferentes domínios da vida"9 (ibidem, p. 35).

Em função dessa afirmativa de Barton, posso dizer que o letramento não diz respeito apenas ao período da alfabetização, mas se estende por toda a vida e depende das práticas sociais que os indivíduos realizam, por mais simples ou complexas que sejam. Assim, como é praticamente impossível alguém ser totalmente iletrado numa sociedade letrada, fica muito difícil prever aonde o processo pode chegar.

\section{O Binômio Proposto por Street: Letramento Autônomo e Ideológico}

Há outros conceitos desenvolvidos por Street que são apresentados no livro Literacy in theory and practice, publicado em 1984, por intermédio dos quais o letramento é definido segundo duas perspectivas: a autônoma e a ideológica. A distinção entre elas questiona a crença anterior de que o letramento da população, como variável autônoma, teria efeitos previsíveis sobre o seu desenvolvimento cognitivo ou sociocultural.

Para Street, o modelo autônomo disfarça as suposições culturais e ideológicas em que se baseia; tem como pressuposto que a escrita, de maneira autônoma, independente de outros fatores, afeta as demais práticas sociais e cognitivas, promovendo benefícios: o desenvolvimento cognitivo, a ascensão social e o progresso econômico.

[Tradução minha]: "People have literacies which they make use of, associated with different domanins of life" (BARTON, 1994, p. 35). 
O modelo de letramento autônomo destaca a preocupação com o desenvolvimento do pensamento abstrato lógico, considera a escrita como um produto completo em si mesmo, vê a oralidade e a escrita como práticas dicotômicas, independentes do contexto de sua produção e pressupõe que há apenas uma maneira de letramento a ser desenvolvida ${ }^{10}$. O uso da escrita é legitimado pelo padrão elitista da norma culta e o modelo que se apresenta como algo neutro, tem um fundo ideológico, porque visa à manutenção do status quo.

É o modelo preferido pelas escolas tradicionais em nossa sociedade e que está associado ao progresso, à mobilidade social. Pauta o ensino por uma progressão ordenada de conhecimentos, ou seja, o indivíduo precisa aprender a falar a língua dominante, assimilar as normas do sistema de escrita para depois usá-las na sociedade, sempre em situações previsíveis e já valorizadas pelo grupo. Segundo essa perspectiva, qualquer indivíduo poderia ter o mesmo desempenho na aquisição e no uso da escrita independentemente do contexto sociocultural a que pertença.

Segundo Street (1984), o modelo é reducionista pelo viés linguístico, autoritário pelo político; uma metodologia etnocêntrica que tem gerado analfabetos funcionais, justamente pela forma como trata o aluno, o qual se torna, via de regra, incapaz de usar a escrita nas interações sociais cotidianas.

Dessa concepção nascem dois grupos cognitivamente distintos: um constituído pelos que sabem ler e escrever e usam esse conhecimento na vida diária e outro constituído pelos que não sabem ler e escrever ou sabem muito pouco para conseguirem usar esses conhecimentos nas práticas de letramento de que participam. O primeiro grupo é o dos letrados e o segundo dos

10 Essa crítica, produzida por Street (1984), está implicada no uso do plural 'letramentos', preferido por diversos estudiosos contemporâneos. Afirma Street: "seria provavelmente, mais apropriado referirmo-nos a 'letramentos' do que a um único letramento, e devemos falar de letramentos, e não de letramento, tanto no sentido de diversas linguagens e escritas, quanto no sentido de múltiplos níveis de habilidades, conhecimentos e crenças, no campo de cada língua e/ou escrita" (STREET, 1984, p. 47). 
não letrados, os quais ainda são responsabilizados pelo próprio fracasso escolar.

Quanto ao modelo ideológico, Street aponta como pressuposto que o letramento é uma prática social e não simplesmente uma habilidade técnica e neutra. Dessa forma, o letramento está vinculado às significações e relações de poder do contexto em que se insere e onde é construído. A partir dessa afirmação fica fácil entender porque Street fala na existência de múltiplos letramentos, que acontecem relacionados às condições socioeconômicas, culturais e políticas e que por isso, variam em cada comunidade.

Como o letramento exerce influência sobre as condições da comunidade em questão, resulta em um processo dinâmico com o passar do tempo, rompendo com a separação dos momentos de aprender e de fazer uso do aprendizado. Esse fenômeno torna o modelo ideológico a concepção mais reveladora das possibilidades das práticas e dos eventos de letramento e aponta outras agências sociais - a família, a igreja, o clube, o local de trabalho, as associações do bairro etc. - como também responsáveis pelos letramentos.

Nesse modelo, a fala e a escrita estão intrinsecamente ligadas, por isso na prática significa ensinar aos alunos a tecnologia da leitura e da escrita, ao mesmo tempo em que oferecer oportunidade de entender o seu processo, bem como o seu resultado, nas interações sociais de que o indivíduo participa. Isso quer dizer, promover o letramento como instrumento de inclusão social, levando o aluno a se tornar um cidadão crítico.

Esses estudos são relativamente novos, por isso têm sido alvos de críticas e de constantes análises, mas é certo que eles contribuem para a compreensão de que todos os letramentos são ideológicos. Além disso, mostra que os estudantes participam de eventos de letramento em diferentes agências sociais, ou seja, a escola não detém o poder de ser a única responsável.

Como já mencionei, o termo letramento também tem sido usado para designar práticas de outra natureza, além das práticas sociais de leitura e escrita. Assim, tem sido constante atualmente 
encontrarmos expressões relacionadas a diversas áreas do saber, tais como: letramento tecnológico, letramento digital, letramento religioso, letramento literário.

\section{Letramento Literário}

Rildo Cosson afirma a necessidade do ensino da literatura na escola, em sua obra Letramento Literário - teoria e prática, a qual aborda o processo de leitura com o objetivo de esclarecer a concepção de leitura que fundamenta o caminho a ser seguido para o letramento literário na escola.

O autor destaca que esse é um processo importante por que não só nos permite saber da vida por meio da experiência do outro, como também vivenciar essa experiência. Diz:

É por possuir essa função maior de tornar o mundo compreensível transformando sua materialidade em palavras de cores, odores, sabores e formas intensamente humanas que a literatura tem e precisa manter um lugar especial nas escolas (COSSON, 2009, p. 17).

Cosson comenta que, em suas passagens por escolas e através de depoimentos de seus alunos de práticas de ensino, constatou que as aulas de literatura, muitas vezes, resumem-se a seguir um livro didático, com uma aula por semana ou uma parte de um período, junto ao Português. São aulas essencialmente informativas, com raras oportunidades de leitura de textos integrais e, eventualmente, seguida de um resumo ou pequeno debate. Com esse enfoque a literatura não está sendo ensinada para garantir sua função essencial de "construir e reconstruir a palavra que nos humaniza” (ibidem, p. 23).

Visto como uma prática social, o letramento literário é responsabilidade da escola. A questão a ser enfrentada, como alerta Cosson, é como fazer "a escolarização da literatura sem descaracterizá-la, sem transformá-la em um simulacro de si mesma que mais nega do que confirma seu poder de humanização" (idem). 
Para alcançar o letramento literário, Cosson afirma que há necessidade de ir além da simples leitura do texto literário. É preciso fazer uma exploração da leitura e cabe à escola ensinar o aluno a fazer essa exploração. Acrescenta o professor,

Ler implica troca de sentidos não só entre o escritor e o leitor, mas também com a sociedade onde ambos estão localizados, pois os sentidos são resultado de compartilhamentos de visões do mundo entre os homens no tempo e no espaço. (ibidem, p. 27).

O sentido do texto só se completa quando acontece o trânsito ou a passagem de sentidos entre o mundo do leitor e o do texto. Para o professor, o texto literário pode produzir um efeito de proximidade, o qual é resultado do diálogo que ele nos permite manter com o mundo e com os outros. Algumas experiências podem parecer únicas para nós, mas Cosson alerta que sua unicidade reside mais no que levamos ao texto do que naquilo que ele nos oferece.

Na mesma obra acima citada, o professor fala dos critérios de seleção dos textos de leitura e indica a pluralidade e diversidade de autores, obras e gêneros como a direção mais popular. É bom lembrar que essa recomendação também faz parte dos textos oficiais sobre o ensino, bem como das teorias da leitura. O principal objetivo dessa prática é a democratização da leitura.

Para realizar a seleção com segurança é necessária a distinção entre contemporâneo e atual, porque o letramento literário trabalhará sempre com o atual, conforme nos ensina Cosson. As obras contemporâneas são aquelas escritas e publicadas em nosso tempo, enquanto as atuais são aquelas que têm significado em nosso tempo, independentemente da época em que foram escritas ou publicadas. A atualidade da obra gera a facilidade ou interesse de leitura do aluno.

Para o letramento literário, ele propõe combinar três critérios de seleção: 1. Não desprezar o cânone, pois esse traz consigo a herança cultural; 2. Não se apoiar somente na contemporaneidade dos textos, mas na atualidade; 3 . Aplicar o princípio da diversidade. 
Antes de entrar no processo de leitura, quero destacar mais um pensamento de Cosson: "é papel de o professor partir daquilo que o aluno já conhece para aquilo que ele desconhece, a fim de proporcionar o crescimento do leitor por meio da ampliação de seus horizontes de leitura" (ibidem, p. 35).

Cosson sistematiza de modo didático a leitura como um fenômeno cognitivo e social e destaca três modos de compreendê-la: por meio de abordagens ascendente, descendente ou conciliatória. Para a primeira a leitura é um processo de extração do sentido que está no texto, para a segunda, o leitor é tomado como centro da leitura, e para a terceira, o leitor é tão importante quanto o texto e a leitura é o resultado de uma interação.

$\mathrm{O}$ alerta de Cosson é para que esses três modos de compreender a leitura sejam pensados como um processo linear. Inicialmente, cito a 'antecipação', que consiste nas várias operações que o leitor faz antes de penetrar no texto propriamente dito, como situar os objetivos da leitura e verificar a materialidade do texto. Outra parte do processo consiste na 'decifração', isto é, o leitor entra no texto através das letras e palavras. Para o leitor maduro, essa etapa passa despercebida, ao contrário do leitor iniciante que despenderá muito tempo nessa etapa. Em seguida, vem a 'interpretação', que é tomada usualmente como sinônimo de leitura, mas seu sentido é restrito às relações estabelecidas pelo leitor, quando processa o texto. O leitor faz inferências do que lê com o conhecimento que tem. O diálogo nesse processo envolve o leitor, o autor e a comunidade. "A interpretação depende, assim, do que escreveu o autor, do que leu o leitor e das convençóes que regulam a leitura em uma determinada sociedade" (ibidem, p. 4l).

É muito importante, no meu ponto de vista, que haja preocupação do professor que indica uma leitura literária não só pela comprovação dessa leitura como por sua ampliação. Pouco acrescenta aos conhecimentos do aluno fazer uma leitura restrita ao texto indicado, sem comentá-la ou relacioná-la a fatos e outras obras. Além disso, as trocas entre colegas ajudarão o aluno a reconhecer a possibilidade de diferentes sentidos para o mesmo texto, enquanto forma uma comunidade de leitores. 
Penso que é com esse objetivo que Cosson (2009) afirma a necessidade de se fazer uma sistematização do processo. E mais, para que a leitura literária seja uma prática significativa para os alunos e para a comunidade em que estão inseridos, tendo em vista sempre a finalidade de letramento literário.

Há duas alternativas de sistematização, conforme Cosson (2009): os trabalhos podem seguir uma sequência básica ou uma sequência expandida, sendo que tanto uma quanto a outra pode ser usada em qualquer série do ensino fundamental ou médio, desde que o professor atente para os objetivos e procedimentos, ajustando-os para cada turma. Em qualquer uma dessas opções o sucesso inicial do encontro do leitor com a obra depende de 'motivação', que não precisa ser necessariamente de ordem temática.

Ainda, recomenda a prática conjunta de atividades de leitura, escrita e oralidade nessa etapa, no entanto, diz que não precisa ser sempre assim. Algumas motivações podem ser exclusivamente orais ou escritas, e a escolha de uma dessas formas depende do tempo que o trabalho tem para ser executado. O professor pode optar pelo uso de material publicitário retirado de jornais e revistas, matéria de revista semanal, piadas, montagem com recortes ou depoimento.

Cosson (2009) mostra constantemente sua preocupação com a prática pedagógica. Ao falar da motivação, alerta que ela exerce influência sobre as expectativas do leitor, mas não tem o poder de determinar sua leitura e que sua é apenas permitir que o aluno receba a obra de uma maneira positiva, e por isso não pode se estender muito.

Após a motivação ou paralelamente a ela, sugere a 'introdução' que é a apresentação do autor e da obra aos alunos. A apresentação física da obra é o momento em que o professor aproveita para chamar a atenção do aluno para a leitura da capa, da orelha, da contracapa e de outros elementos paratextuais (algumas edições possuem apreciações críticas, prefácios, notas sobre o autor etc.) que introduzem a obra. Isso deve ser feito de forma coletiva e quando possível de forma a comparar ediçôes diferentes. 
A etapa seguinte é a 'leitura', a qual não pode prescindir de um acompanhamento. Cosson recomenda aos professores que na apresentação da obra 'negociem' com seus alunos o tempo para a leitura. Dependendo da extensão da obra, das habilidades leitoras dos alunos podem determinar, em conjunto, o que ele chama de 'intervalos', quantos são convenientes e a margem temporal entre eles.

Os intervalos podem ser de natureza variada, ou seja, o professor pode propor a leitura de textos menores, focalizando o mesmo tema, pode convidar os alunos a fazer uma leitura conjunta de um capítulo ou trecho de um capítulo e proceder a uma microanálise estilística ou outra atividade que o trabalho permita. A importância dos intervalos reside no fato de que é possível, nesses momentos, ao professor observar os alunos e atender àqueles que demonstrarem mais dificuldades na leitura.

Após a leitura vem a 'interpretação', que é uma fase onde não há restrições. As atividades dessa fase precisam ter como princípio a externalização da leitura, isto é, o seu registro. É uma fase importante do trabalho porque, segundo Cosson "[...] a interpretação parte do entretecimento dos enunciados, que constituem as inferências, para chegar à construção do sentido do texto, dentro de um diálogo que envolve autor, leitor e comunidade" (ibidem, p. 64).

Pensando no letramento literário, Cosson recomenda que a interpretação se efetive em dois momentos: um interior e outro exterior. O 'momento interior', de caráter individual, é aquele que acompanha a decifração, é o encontro do leitor com a obra. Não pode ser substituído por nenhum mecanismo pedagógico, como ver o filme com a adaptação da história ou ler um resumo da internet. A motivação, a introdução e a leitura são os elementos de interferência da escola no letramento literário. A interpretação é feita com o que somos no momento da leitura, mesmo que pareça pessoal o momento interno, continua sendo um ato social. O 'momento externo' é a concretização ou a materialização da interpretação como ato de construção de sentido em uma determinada comunidade. 
$\mathrm{Na}$ apresentação da interpretação ou em sua avaliação o professor precisa tomar cuidado. Não cabe supor que exista apenas uma interpretação para cada leitura, aquela que o professor entendeu ou leu, ou ainda que deva aceitar tudo o que o aluno disser, como se qualquer interpretação fosse válida.

Quanto ao registro das interpretaçôes, Cosson recomenda o uso da resenha, porque considera que esse recurso tem vários benefícios, mas as possibilidades de registro de interpretação são diversificadas e dependem de muitos fatores: turma, objetivos do professor, textos escolhidos etc. Outra sugestão é que, quando o texto estiver pronto, circule entre os colegas.

Porém, cabe uma ressalva: o uso excessivo da resenha pode 'engessar' o letramento literário e automatizar a resposta do aluno à leitura. Então, o professor pode alternar outras atividades, orientando os alunos a criar um capítulo a mais no final, inserir um período temporal na narrativa, (por exemplo, o que acontece com as personagens dez anos depois), sugerir alteração do espaço ou reescrever o final.

De forma objetiva posso dizer que os passos da sequência básica acima descrita são quatro: Motivação, Introdução, Leitura e Interpretação. E acrescento um esclarecimento de Cosson:

[...] na sequência básica se realiza a aprendizagem plena da literatura, mas porque nela se enfatiza a experiência da interpretação como construção de sentido do mundo, as outras dimensões do letramento literário terminam por ocupar um segundo plano (ibidem, p. 76).

Por isso Cosson propõe a sequência expandida, que deixa mais evidente algumas articulações entre o saber literário e o horizonte desse letramento na escola. Os passos dessa sequência incluem: Motivação, Introdução, Leitura, Primeira Interpretação, Contextualização, Segunda Interpretação e Expansão. A 'motivação' pode ser feita da mesma forma em qualquer uma das sequências, por isso não vou repeti-la.

Quanto à 'introdução', Cosson indica três alternativas: a primeira é através de uma entrada temática, a segunda, é o aproveitamento do acervo da biblioteca e a terceira é a leitura das primeiras 
páginas da obra em aula para apresentação das personagens. Essas opções podem ser ampliadas com a leitura de prefácios, orelhas e outros textos que constituem a apresentação do livro.

A 'leitura' é o passo que segue a introdução da obra e deve ser feita prioritariamente extraclasse. O professor deve estabelecer um sistema de verificação de leitura que pode ser feito por meio de intervalos, como na sequência básica. Para esses intervalos o professor pode buscar apoio na leitura de uma canção ou de um conto ou ainda na de uma imagem ou foto. O ideal, diz Cosson (2009), é que a leitura do intervalo só seja relacionada com o tema do texto principal no final da atividade dos intervalos. A diversidade de leituras que podem ser realizadas nos intervalos mostra que não há limites ou imposições na seleção de textos, além de mostrar que o literário dialoga com outros textos.

A 'interpretação’ destina-se à apreensão global da obra. As atividades ideais para essa etapa podem ser um depoimento ou um ensaio. Aqui o professor pode deixar os alunos dizerem o que pensam da obra, sem muita rigidez na forma. Outra técnica é a entrevista. A primeira interpretação traz uma característica de fechamento, é o momento de resposta à obra, por isso deve ser feita em sala de aula, mas não deve ser conduzida como avaliação da obra. Nessa etapa, Cosson não aconselha debates ou atividades em grupo.

Um cuidado é necessário nessa fase dos trabalhos: algum aluno pode tentar responder de forma muito resumida ou afirmar que não tem nada a dizer. Cabe ao professor não aceitar um julgamento sumário ou uma omissão e mostrar ao aluno a importância da sua participação na construção do seu próprio conhecimento literário.

A ‘contextualização' traz consigo uma característica que considero profundamente enriquecedora: sua abrangência, já que ela pode ser ampliada, dividida ou reconfigurada. Conforme Cosson (2009), o número de contextos a serem explorados na leitura de uma obra é teoricamente ilimitado, mas o professor indica um caminho, pois apresenta sete possibilidades de contextualização: 
- A 'contextualização teórica' procura tornar explícitas as ideias que sustentam a obra, os conceitos fundamentais que estão ali representados.

- A 'contextualização histórica' enquadra a obra na época que ela encena ou no período de sua publicação e pode desdobrarse em várias outras, segundo os interesses dos alunos (biográfica, editorial etc.).

- A 'contextualização estilística' está centrada nos períodos (ou estilos) literários, mas precisa ir além da identificação das características dos movimentos, é preciso ver as características da obra em si mesma, pois os períodos literários são abstrações e nenhuma obra se identifica inteiramente com o período.

- A 'contextualização poética' procura observar a composição da obra, como ela está estruturada, quais os princípios de sua organização, mas seu estudo não se restringe a uma catalogação de itens.

- A 'contextualização crítica' trata da recepção de determinado texto literário, pode se ocupar da crítica ou da edição da obra. É a análise de outras leituras que tem por objetivo contribuir para a ampliação do horizonte de leitura da turma.

- A 'contextualização presentificadora' desperta a atenção do aluno para obra ou desperta seu interesse pela leitura, evidenciando o tema e as relações dele com o presente, que podem ser expressas em semelhanças ou diferenças.

- A 'contextualização temática' vê a repercussão do tema dentro da obra. Mas esse trabalho precisa ser rigorosamente delimitado para que o estudo não passe a ser do tema e não da obra literária.

Cosson (2009) ressalta que é conveniente que a contextualização seja feita por meio de uma pesquisa, com diferentes formas de coleta de informações, como: entrevistas, levantamento na internet, consulta bibliográfica etc. e que essas atividades sejam planejadas pelos alunos e apresentem registros por escrito, mesmo quando a opção recair em um debate. E, ainda, o próximo passo da sequência expandida poderá transcorrer melhor se os resultados dessa pesquisa forem compartilhados na turma. 
A 'segunda interpretação' objetiva a leitura aprofundada de um de seus aspectos como uma personagem, um tema, um traço estilístico, uma correspondência com questões contemporâneas, questões históricas ou outra característica de acordo com a obra ou com os objetivos do trabalho. Essa etapa pode ser realizada individualmente ou em grupo.

Cosson (2009) sugere duas possibilidades de realização deste trabalho: a primeira delas é uma integração entre as duas etapas, incorporando a presente pesquisa à primeira interpretação. A segunda, através de um projeto, que deve ser formal, isto é, deve apresentar todas as partes que o constituem - título, objetivos, justificativas, procedimentos, cronograma, referências; podendo até incluir hipóteses.

$\mathrm{O}$ registro final evidencia o aprofundamento da leitura e pode ser um ensaio após apresentação de todos os trabalhos, uma exposição de cartazes nos murais da escola, seminários com a presença de público externo à turma, confecção de um livro, ou o registro do projeto, quando for o caso. Neste ponto, penso que os recursos de que o professor dispõe são determinantes para a escolha de uma dessas opções ou de outra que se torne viável.

Essa prática tem vários benefícios no processo de letramento, proporciona mais autonomia na leitura da obra, gera maior equilíbrio entre as partes, traz harmonia e coerência e facilita o processo de avaliação. Mas o mais importante é que a 'segunda interpretação' deve resultar em compartilhamento da leitura, pois este é o ponto alto do letramento na escola. Como anuncia Cosson (2009), "É o reconhecimento de que uma obra literária não se esgota antes se amplia, e se renova pelas várias abordagens que suscita, que identifica o leitor literário" (ibidem, p. 94).

Esta fase termina o trabalho de leitura com a obra. A seguir, Cosson (2009) indica a 'expansão', que se torna uma ultrapassagem do limite da obra para outros textos. A expansão pode ser vista tanto como uma extrapolação dentro do processo de leitura como a realização de intertextualidade no campo literário. Por isso esta fase busca destacar as possibilidades de diálogo que 
toda obra articula com os textos que a precederam, ou os que lhes são contemporâneos ou posteriores.

Desde que o professor ressalte a adequação ao novo gênero, no processo de expansão não há contraindicação de assistir a filmes ou minisséries televisivas que foram baseados na obra, diferentemente das fases anteriores. Com a atividade assim encaminhada o trabalho da expansão se torna essencialmente comparativo.

A 'expansão' também pode servir para reiniciar a sequência, funcionando como motivação para a próxima. Como a sequência básica está inserida na expandida, cabe ao professor estabelecer o caminho para um letramento literário adequado ao seu grupo de alunos e à sua escola. Não é possível estabelecer um caminho único, as sequências podem ser alteradas, outras sequências podem ser criadas de acordo com os objetivos do trabalho e das condições do grupo, bem como dos recursos oferecidos pela escola.

A sequência expandida, como vimos pela apresentação das partes que a compõe, toma um tempo razoável. Esta é uma das preocupações de alguns professores; mas, para o letramento literário, a qualidade do trabalho deve-se sobrepor à quantidade de obras lidas. Cosson (2009) reforça que o propósito do trabalho é justamente promover o letramento literário por meio de um caminho que o aluno possa fazer sozinho com outros tantos textos que ele venha a ler no futuro.

\section{Considerações finais}

Quero retomar um tema já mencionado anteriormente, mas que, por sua importância, merece nova abordagem. O objetivo do letramento literário na escola é formar uma comunidade de leitores, que não sejam meros consumidores de cultura, mas que com ela dialoguem. Estes leitores precisam aprender a tratar os textos literários segundo os interesses da sua comunidade cultural. 
Os alunos e os professores já estão acostumados a que os trabalhos realizados em sala de aula sejam avaliados. Assim, os primeiros fazem as tarefas porque receberão notas, a aprendizagem fica em segundo plano; e os últimos se preparam para criar formas de avaliar para atribuir tais notas, sem se dar conta de que as atividades de avaliação são índices que permitem a análise do desempenho do aluno, mas também do professor e da escola.

Nos trabalhos com as sequências que descrevi, há vários momentos em que o professor pode avaliar o desempenho de seus alunos, de forma natural, sem que haja a preocupação com teste ou prova de leitura. Nas aulas de literatura, Cosson (2009) diz que o aluno ainda é visto "como mero receptor do conteúdo texto ou das informações do professor, [e] o processo de avaliação tende a acompanhar essa orientação" (ibidem, p. 112).

A comprovação da leitura se torna uma preocupação e geralmente as questóes giram em torno de dados textuais, eventualmente com uma pergunta final sobre a posição do aluno sobre determinada situação ou sobre o final da obra. A avaliação que assim procede só comprova que o aluno é capaz de reproduzir informações, e aceitar qualquer resposta, porque se trata de opinião, desvaloriza a leitura do aluno.

A proposta apresentada favorece a avaliação em diferentes momentos do processo de leitura. Há três grandes pontos de apoio na sequência básica: os intervalos, a discussão e o registro da interpretação. Na sequência expandida, dois pontos na segunda interpretação e mais um no registro da expansão. E principalmente, é conveniente que o professor se preocupe de modo preferencial com o conteúdo da resposta em lugar das formas e não é conveniente que a produção escrita seja um mero pretexto para a correção da norma culta.

\section{Referências}

BARTON, David. Literacy: an introduction to the ecology of witten language. 2. ed. Oxford: Blackwell Publishing, 2007. 
. Literacy: an introduction to the Ecology of written language. Cambridge: Blackwell, 1994.

COSSON, Rildo. Letramento literário: teoria e prática. São Paulo: Contexto, 2009.

HEATH, Shirley Brice. What no bedtime story means: narrative skills at home and school. In: DURANTI, A. (Org.) Linguistic Anthropology: a reader. Oxford: Blackwel, p. 318-342, 2001.

. Ways with words: Language, life and work in communities and classrooms. Cambridge England; New York: Cambridge University Press: 1996; 1983.

. Protean Shapes in Literacy Events: Ever-Shifting Oral and Literate Traditions. In: TANNEN, D. (Edl.) Spoken and written language: exploring orality and literacy. Norwood (N.J.): Ablex, p. 91-117, 1982.

INAF. Instituto Paulo Montenegro. [s/d]. Disponível em: <http://www. ipm.org.br/ipmb_pagina.php?mpg=4.01.00.00.00\&ver=por) $>$. Acesso em: 20 jan. 2011.

KATO, Mary. No mundo da escrita: uma perspectiva psicolingüística. 5. ed. São Paulo: Ática, 1998.

KLEIMAN, Ângela. Os significados do letramento: uma nova perspectiva sobre a prática social da escrita. São Paulo/Campinas: Mercado das Letras, 1995.

OLIVEIRA, Marta Kohl de; VÓVIO, Cláudia Lemos. Homogeneidade e heterogeneidade nas configurações do alfabetismo. In: RIBEIRO, Vera Masagão. (Org.). Letramento no Brasil: reflexões a partir do INAF 2001. São Paulo: Global, 2003.

RIBEIRO, Vera Masagão. (Org.). Letramento no Brasil: reflexões a partir do INAF 2001. São Paulo: Global, 2003.

SOARES, Magda. Letramento e escolarização. In: RIBEIRO, Vera Masagão. Letramento no Brasil: reflexões a partir do INAF 2001. São Paulo: Global, p. 89-113, 2003.

Letramento: um tema em três gêneros. Belo Horizonte: CEALE/ Autêntica, 1998. 
STREET, Brian V. Literacy in Theory and Practice. Cambridge: Cambridge University Press, 1984.

TFOUNI, Leda Maria Verdiani. Adultos não alfabetizados: o avesso do avesso. Campinas: Pontes, 1988.

. Adultos não-alfabetizados em uma sociedade letrada. v. 1. São Paulo: Cortez Editora, 2006.

. Letramento e alfabetização. São Paulo: Cortez, 1995. 